\title{
ITEM ADAPTIF MENGGUNAKAN LOGIKA FUZZY MAMDANI PADA GAME BERTEMA KEBERSIHAN SUNGAI
}

\section{ADAPTIVE ITEM USING MAMDANI FUZZY LOGIC IN RIVER SANITATION THEMED GAME}

\author{
Septian Idhi Pangestu ${ }^{1}$ \\ Hanny Haryanto ${ }^{2}$ \\ Erlin Dolphina ${ }^{3}$ \\ 1,2,3Jurusan Teknik Informatika, Fakultas Ilmu Komputer, UniversitasDian Nuswantoro \\ Jl. ImamBonjol207Semarang \\ Telp.(024)3517261/Fax. (024)3569684 \\ e-mail: ${ }^{1} 111201307669 @$ mhs.dinus.ac.id, ${ }^{2}$ hanny.haryanto@dsn.dinus.ac.id, \\ erlin.dolphina@dsn.dinus.ac.id
}

\begin{abstract}
ABSTRAK
Indonesia merupakan negara yang memiliki tingkat biodiversitas yang tinggi, ditandai dengan keanekaragaman hayatinya. Keanekaragaman hayati tersebut perlu untuk dijaga kelestariannya. Salah satu yang perlu dijaga adalah kebersihan lingkungan sungai dari pencemaran khususnya sampah. Akan tetapi kesadaran masyarakat Indonesia untuk tidak membuang sampah di sungai masih kurang. Maka diperlukan adanya sosialisasi atau pembelajaran untuk meningkatkan kesadaran masyarakat. Salah satu media yang dapat digunakan untuk pembelajaran adalah game karena dalam game akan terjadi interaksi antara pemain dan komputer dengan caramenyenangkan. Dalam game, terdapat sebuah objek yang berguna untuk membantu pemain dalam menyelesaikan game yang disebut item. Item akan muncul secara acak atau sesuai dengan konfigurasi yang ditentukan developer. Hal ini kurang efektif karena apabila item tidak muncul atau item yang muncul tidak sesuai kebutuhan pemain maka pemain akan kesulitan dan cenderung mengalami kegagalan dalam menyelesaikan game. Metode Fuzzy Mamdani digunakan untuk menentukan jenis item yang muncul sesuai dengan apa yang saat itu dibutuhkan oleh pemain. Input diperoleh dari nilai sisa health pemain, sisa health laut, serta jumlah kesalahan yang dilakukan pemain, sedangkan output yang dihasilkan berupa item yang dibutuhkan oleh pemain. Hasil akhir dari penerapan metode tersebut menjadikan kemunculan item lebih adaptif dengan kebutuhan pemain.
\end{abstract}

Kata kunci : Game, Kebersihan, Sungai, Sampah, Fuzzy Mamdani, Item

\begin{abstract}
Indonesia is characterized by its biodiversity. Such biodiversityneeds to be preserved. One that needs to be taken care of is the cleanliness of the river environment frompollution, especially waste. However, the awareness of Indonesian people not to throw garbage in the river isstill lacking. It is necessary for socialization to increase public awareness. Gamecan be used for learning because it will encourage fun interaction between players and computers. In the game, itemswill appear randomly or in accordance with the configuration specified by the developer. This is less effective because if the item does not appear or the item that appears does not match the needs of players thenplayers will be difficult and tend to experience failure in completing the game. Fuzzy Mamdani method isused to determine the type of item that appears in accordance with what is currently required by the player.Input is
\end{abstract}


derived from the residual health value of the player, the remaining marine health, as well as thenumber of mistakes made by the player, while the output is an item required by the player. The result makes the appearance of items more adaptive to players needs.

Keywords : Game, Sanitation, River, Garbage, Fuzzy Mamdani, Item

\section{PENDAHULUAN}

Indonesia merupakan suatu negara kepulauan yang kaya akan sumber daya alam, dan juga keanekaragaman hayati. Bersamaan dengan hal tersebut, lingkungan hidup juga wajib untuk dijaga agar keanekaragaman tetap terjaga. Salah satu cara untuk menjaga lingkungan tetap bersih adalah dengan mengurangi polusi, baik polusi udara, polusi tanah, dan polusi air.Polusi yang cukup menjadi masalah dalam lingkungan adalah polusi air. Polusi tersebut berkaitan dengan banyaknya sampah yang menumpuk di aliran sungai. Banyaknya sampah di sungai menimbulkan berbagai macam masalah diantaranya adalah timbulnya bencana banjir. Di Indonesia, bencana banjir menempati urutan pertama sebagai bencana yang sering terjadi berdasarkan laporan hingga Februari 2017 oleh Badan Nasional Penanggulangan Bencana (BNPB), dengan persentase $31,4 \%$, diikuti bencana puting beliung dengan persentase $21,2 \%$ [1].

Pendidikan untuk meningkatkan kepedulian terhadap lingkungan sangat penting diberikan pada masyarakat Indonesia terutama masyarakat yang masih berusia dini agar masyarakat sungguh-sungguh memahami makna penting dari menjaga kebersihan, dan kelestarian lingkungan untuk mencegah terjadinya bencana yang dapat merugikan masyarakat itu sendiri serta mencegah rusaknya ekosistem sebagai akibat dari polusi/pencemaran air. Disamping itu, sebagai bagian dari pendidikan tentang betapa pentingnya. Media yang dapat digunakan sebagai alternatif dalam pembelajaran adalah game digital atau video games [2].Media game digitaldigunakanagar sosialisasi dapat dilakukan dengan cara yang lebih menyenangkan serta pesan yang ingin disampaikan dapat tersalurkan dengan baik [3]

Dalam sebuah game, terdapat kontenitemyang digunakan untuk membantu seorang pemain agar dapat menyelesaikan sebuah tugas atau misi yang diberikan dalam game. Pada umumnya collectible-item akan muncul secara statis yang artinya item tersebut hanya muncul atau dapat diperoleh pada tempat-tempat tertentu yang telah ditentukan oleh pihak pengembang. Hal ini dapat menimbulkan ketidakefektifan kegunaan dari item itu sendiri. Maka dari itu, penelitian dilakukan untuk menjadikan kemunculan item lebih adaptive atau dapat menyesuaikan apa yang dibutuhkan oleh pengguna. Agar kemunculan item lebih adpative maka digunakan logika Fuzzy Mamdani pada game yang dibuat. Alasan pemilihan logika Fuzzy Mamdani adalah karena logika Fuzzy Mamdani memiliki tingkat akurasi yang cukup baik [4].

Penelitian yang berkaitan dengan adaptive game telah dilakukan sebelumnya oleh Ardiawan Bagus Harisa, dimana pada penelitian tersebut fungsi adaptive diterapkan pada tingkat kesulitan dalam game dengan menggunakan algoritma fuzzy Sugeno yang dikombinasikan dengan Neural Network atau jaringan saraf buatan. Penelitian tersebut bertujuan agar game yang dibuat memiliki tingkat kesulitan yang dapat berubah secara otomatis sesuai dengan kemampuan atau pengalaman bermain dari pengguna/pemain [5]. [6] menerapkan Finite State Machine (FSM) untuk mengatur perilaku musuh pada game pendidikan untuk mengenal unsur kimia. Kemudian [7] menggunakan metode serupa untuk membentuk perilaku reward game. 


\section{METODE PENELITIAN}

Metode yang digunakan dalam penelitian adalah logika Fuzzy Mamdani. Dimana penelitian dilakukan melalui beberapa tahapan sebagai berikut :

1. Penentuan parameter input \&output serta fungsi keanggotaannya (Fuzzifikasi)

Parameter inputyang digunakan adalah sebagai berikut :

1. HPK :\{sedikit, cukup, banyak\}

Parameter yang merepresentasikan sisa Health Point yang dimiliki karakter utama

$$
\begin{aligned}
& S E D I K I T=\left\{\begin{array}{cc}
1_{j} & H P K \leq 30 \\
\frac{48-1 Y P K}{48-x x_{j}} & 30<H P K<45 \\
0 ; & H P K \geq 45
\end{array}\right.
\end{aligned}
$$

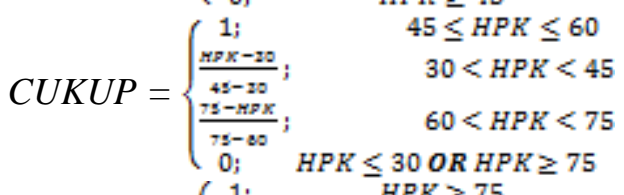

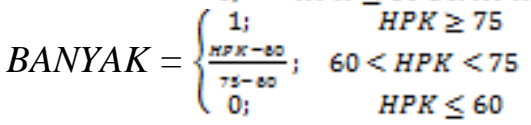

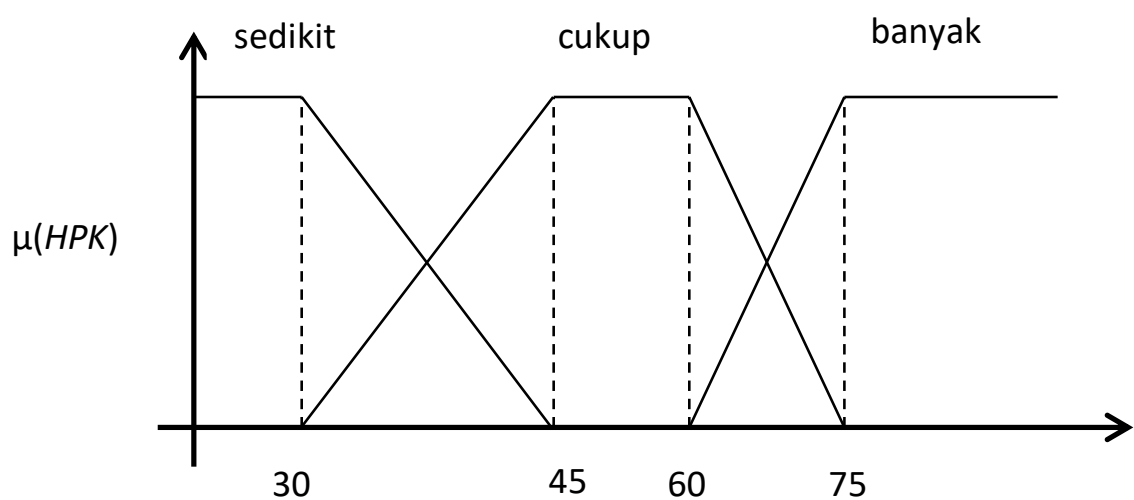

Gambar 1 Himpunan Fuzzy variabel Health Point Kapal

2. HPL : \{sedikit, cukup, banyak\}

Parameter yang merepresentasikan sisa Health Point dari laut

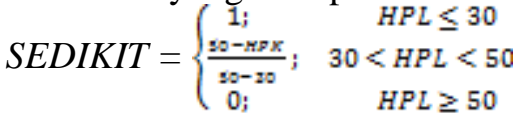

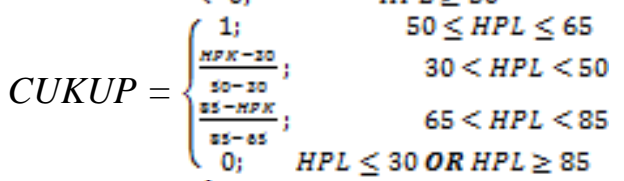

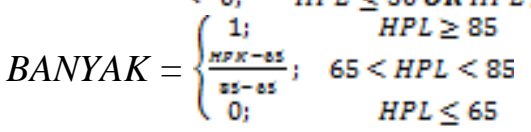




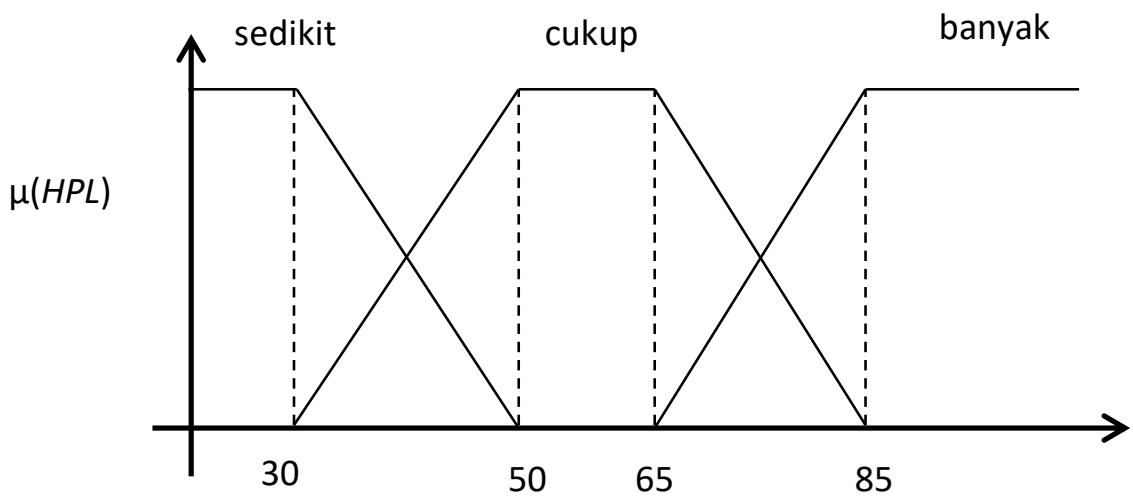

Gambar 2 Himpunan Fuzzy variabel Health Point Kapal

3. FAIL : \{jarang, kadang, sering $\}$

Parameter yang merepresentasikan seberapa banyak kesalahan yang dilakukan pemain

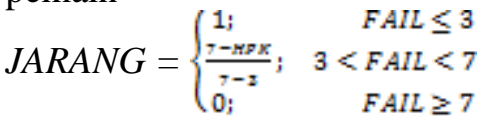

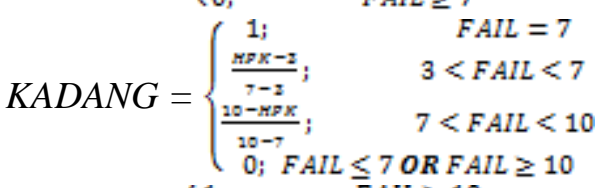

$$
\begin{aligned}
& \text { SERING }=\left\{\begin{array}{lc}
1, & \text { FAIL } \geq 10 \\
\frac{15 F-7}{30-7} ; & 7<\text { FAIL }<10 \\
0 ; & \text { FAIL } \leq 7
\end{array}\right.
\end{aligned}
$$

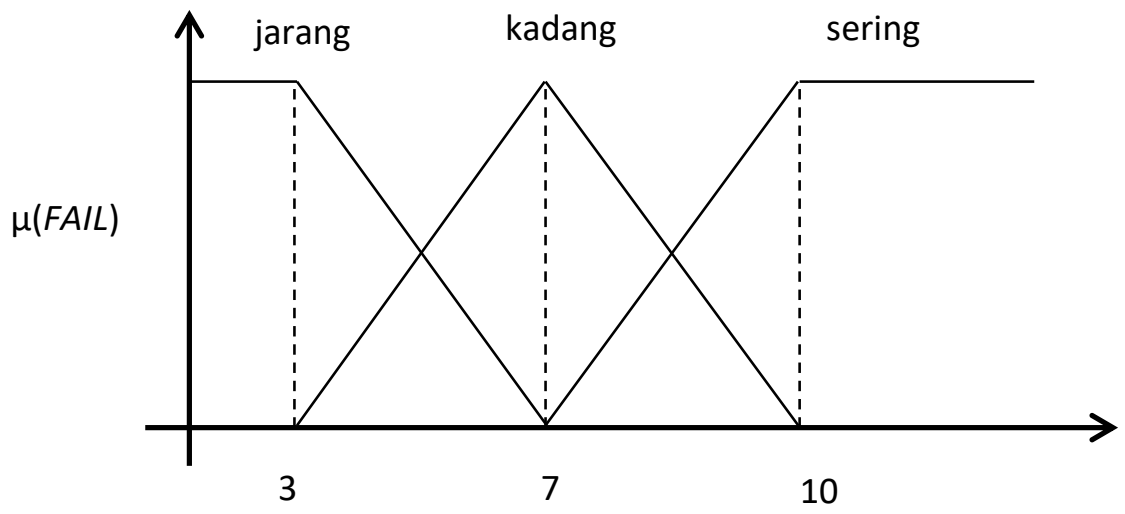

Gambar 3 Himpunan Fuzzy variabel Kesalahan pemain (FAIL)

Parameter output yang dihasilkan akan merepresentasikan jenis item yang akan muncul. Parameter tersebut adalah :

1. Item penambah HPK (ADD_HPK)

2. Item penambah HPL (ADD_HPL)

3. Item pemerlambat permainan (SLOW)

4. Item pengganda skor yang diperoleh (DOUBLE)

Masing-masing parameter memiliki grafik keanggotaan yang sama 


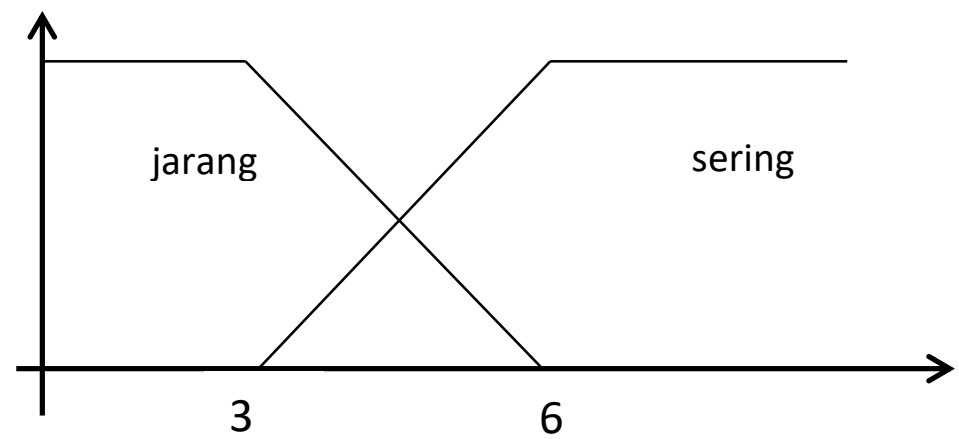

Gambar 4 Grafik keanggotaan untuk paramter output

4. Menentukan Rule/Aturan

Dalam menentukan rule akan digunakan rumus $A^{n}$, karena pada penelitian yang dilakukan menggunakan 3 variabel dan 3 himpunan Fuzzy maka, rule optimal yang mungkin terbentuk adalah $3^{3}$. Berikut rule untuk rekomendasi item :

Tabel 1 Tabel Rules

\begin{tabular}{|c|c|c|c|c|c|c|}
\hline \multirow{2}{*}{$H P K$} & \multirow{2}{*}{$H P L$} & \multirow{2}{*}{ FAIL } & \multicolumn{4}{|c|}{ ITEM_KIND } \\
\hline & & & $A D D \_H P K$ & $A D D \_H P L$ & SLOW & DOUBLE \\
\hline SEDIKIT & SEDIKIT & JARANG & Sering & Sering & Jarang & Jarang \\
\hline SEDIKIT & SEDIKIT & KADANG & Sering & Sering & Jarang & Jarang \\
\hline SEDIKIT & SEDIKIT & SERING & Sering & Sering & Sering & Jarang \\
\hline SEDIKIT & CUKUP & JARANG & Sering & Jarang & Jarang & Jarang \\
\hline SEDIKIT & CUKUP & KADANG & Sering & Jarang & Jarang & Jarang \\
\hline SEDIKIT & CUKUP & SERING & Sering & Jarang & Sering & Jarang \\
\hline SEDIKIT & BANYAK & JARANG & Sering & Jarang & Jarang & Jarang \\
\hline SEDIKIT & BANYAK & KADANG & Sering & Jarang & Jarang & Jarang \\
\hline SEDIKIT & BANYAK & SERING & Sering & Jarang & Sering & Jarang \\
\hline CUKUP & SEDIKIT & JARANG & Jarang & Sering & Jarang & Jarang \\
\hline CUKUP & SEDIKIT & KADANG & Jarang & Sering & Jarang & Jarang \\
\hline CUKUP & SEDIKIT & SERING & Jarang & Sering & Sering & Jarang \\
\hline
\end{tabular}


ISSN : 1978 -8282

\begin{tabular}{|c|c|c|c|c|c|c|}
\hline CUKUP & CUKUP & JARANG & Jarang & Jarang & Jarang & Sering \\
\hline CUKUP & CUKUP & KADANG & Jarang & Jarang & Jarang & Sering \\
\hline CUKUP & CUKUP & SERING & Jarang & Jarang & Sering & Jarang \\
\hline CUKUP & BANYAK & JARANG & Jarang & Jarang & Jarang & Sering \\
\hline CUKUP & BANYAK & KADANG & Jarang & Jarang & Jarang & Sering \\
\hline CUKUP & BANYAK & SERING & Jarang & Jarang & Sering & Jarang \\
\hline BANYAK & SEDIKIT & JARANG & Jarang & Sering & Jarang & Jarang \\
\hline BANYAK & SEDIKIT & KADANG & Jarang & Sering & Jarang & Jarang \\
\hline BANYAK & SEDIKIT & SERING & Jarang & Sering & Sering & Jarang \\
\hline BANYAK & CUKUP & JARANG & Jarang & Jarang & Jarang & Sering \\
\hline BANYAK & CUKUP & KADANG & Jarang & Jarang & Jarang & Sering \\
\hline BANYAK & CUKUP & SERING & Jarang & Jarang & Sering & Jarang \\
\hline BANYAK & BANYAK & JARANG & Jarang & Jarang & Jarang & Sering \\
\hline BANYAK & BANYAK & KADANG & Jarang & Jarang & Jarang & Jarang \\
\hline BANYAK & BANYAK & SERING & Jarang & Jarang & Sering & Jarang \\
\hline
\end{tabular}

5. Penghitungan Defuzzifikasi

Merupakan tahapan yang dilakukan untuk mengubah data output berupa rekomendasi item berdasarkan rule yang telah ditentukan sebelumnya menjadi data numerik. Rumus untuk mengubah data tersebut adalah sebagai berikut:

$$
\mathrm{y}=\frac{\sum y \mu_{R}(y)}{\sum \mu_{R}(y)}
$$




\section{HASIL DAN PEMBAHASAN}

Pada penelitian yang dilakukan, menghasilkan sebuah game yang bertema kebersihan linkungan yang telah diterapkan logika fuzzy mamdani untuk membuat tingkat kemunculan item menjadi adaptif atau dapat menyesuaikan dengan kebutuhan pemain

1. Game

Latar belakang game akan berlokasi pada suatu aliran sungai dengan daratan pada bagian tepinya.Tugas pemain dalam game adalah mengumpulkan skor tertinggi dengan mengumpulkan objek berupa sampah dengan jenis-jenis yang telah disebutkan sebelumnya. Selama permainan pemain dapat mengerakkan karakter secara bebas serta mampu mengubah status karakter sesuai jenis objek yang harus diambil. jenis objek yang diambil akan selalu muncul secara acak tanpa bisa diperkirakan oleh pemain, serta titik kemunculan objek dipilih secara acak berdasarkan titik-titik yang telah ditentukan sebelumnya. Kecepatan permainan akan meningkat ketika pemain mampu mencapai skor tertentu.

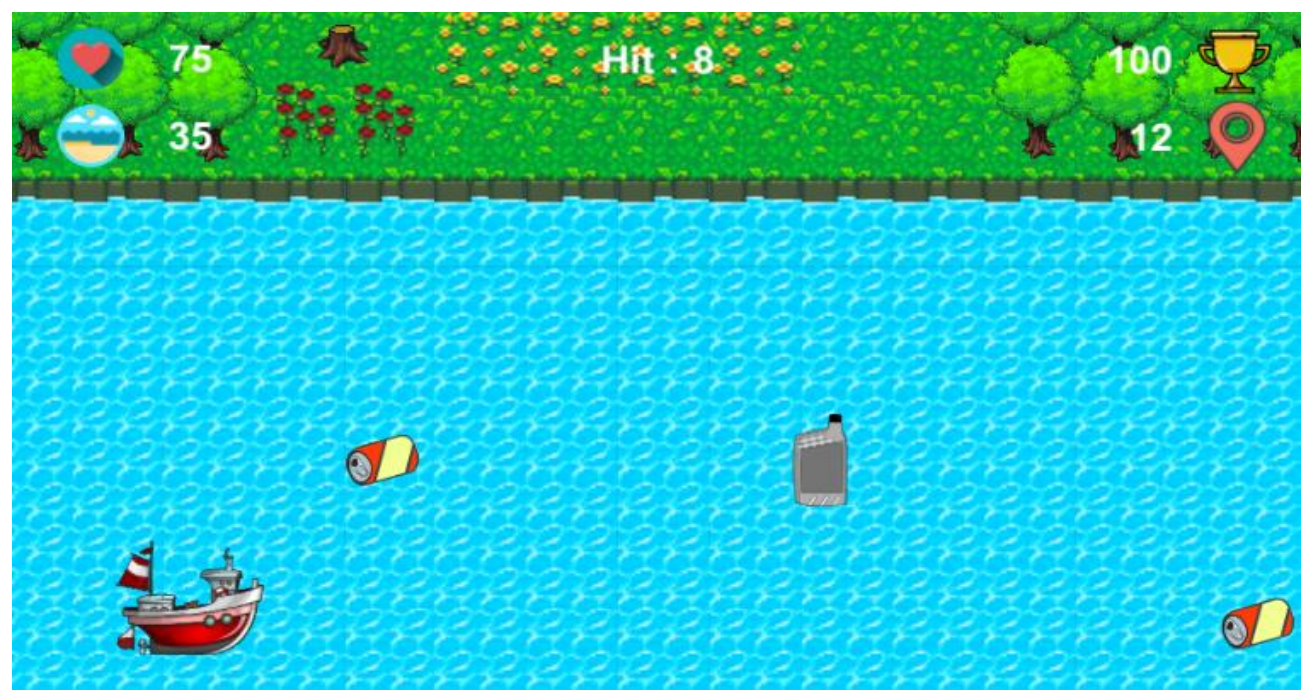

Gambar 5. Tampilan Permainan

2. Logika Fuzzy Mamdani

Algoritma fuzzy yang telah diterapkan akan memulai proses kalkulasi ketika pemain telah bertahan dalam permainan dalam kurun waktu tertentu. Untuk mengamati perilaku jenis output yang dihasilkan, maka dilakukan beberapa pengujian. Pengujian dilakukan dengan mendeklarasikan terlebuh dahulu nilai dari masing-masing parameter input yang telah ditentukan

Pengujian pertama dilakukan dengan mengambil sampel input sebesar 75 untuk health point pemain (HPK), 35 untuk health point laut (HPL), dan 8 kali kesalahan yang dilakukan oleh pemain (FAIL). Maka proses fuzzifikasi dapat dijabarkan sebagai berikut :

Derajat keanggotaan dari health point pemain (HPK) adalah :

$$
\begin{aligned}
& \mu_{\text {HPK_Cukup }}[75]=0 \\
& \mu_{\text {HPK_Banyak }}[75]=1(3)
\end{aligned}
$$

Derajat keanggotaan dari health point laut (HPL) adalah :

$$
\mu_{\text {HPL_Sedikit }}[35]=\frac{50-35}{50-30}=0,75
$$




$$
\mu_{\text {HPL_Cukup }}[35]=\frac{35-30}{50-30}=0,25
$$

Derajat keanggotaan dari jumlah kesalahan pemain (FAIL) adalah :

$$
\begin{aligned}
& \mu_{\text {FAIL_Kadang }}[8]=\frac{10-8}{10-7}=0,67 \\
& \mu_{\text {FAIL_Sering }}[8]=\frac{8-7}{10-7}=0,33
\end{aligned}
$$

Setelah hasil dari proses fuzzifikasi diperoleh maka dilakukan proses inferensi rules. Masing-masing derajat keanggotaan akan dilakukan operasi AND dan operasi MIN berdasarkan aturan yang telah ditentukan. Berdasarkan hasil perhitungan pada masingmasing derajat keanggotaan maka rule yang memenuhi adalah rule 20, 21, 23, 24

1. IF HPK BANYAK AND HPL SEDIKIT AND FAIL KADANG THEN ADD_HPK JARANG, ADD_HPL SERING, SLOW JARANG, DOUBLE JARANG $\alpha$ - predikat $_{20}=\mu_{\text {HPK_Banyak }} \cap \mu_{\text {HPL_Sadikit }} \cap \mu_{\text {FAlL_Kadang }}$

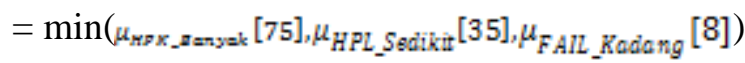

$$
\begin{aligned}
& =\min (1 ; 0,75 ; 0,67) \\
& =0,67
\end{aligned}
$$

2. IF HPK BANYAK AND HPL SEDIKIT AND FAIL SERING THEN ADD_HPK JARANG, ADD_HPL SERING, SLOW SERING, DOUBLE JARANG

$$
\begin{aligned}
& \alpha-\text { predikat }_{21}=\mu_{\text {HPK_Banyak }} \cap \mu_{\text {HPL_Sedikit }} \cap \mu_{\text {FAIL_Sering }}
\end{aligned}
$$

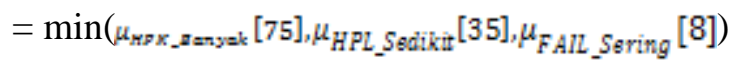

$$
\begin{aligned}
& =\min (1 ; 0,75 ; 0,33) \\
& =0,33
\end{aligned}
$$

3. IF HPK BANYAK AND HPL CUKUP AND FAIL KADANG THEN ADD_HPK JARANG, ADD_HPL JARANG, SLOW JARANG, DOUBLE SERING

$$
\begin{aligned}
& \alpha \text { - } \text { predikat }_{23}=\mu_{\text {HPK_Banyak }} \cap \mu_{\text {HPL_Cukup }} \cap \mu_{\text {FAIL_Kadang }}
\end{aligned}
$$

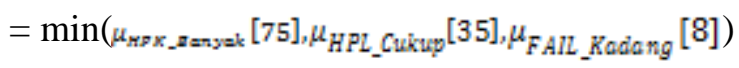

$$
\begin{aligned}
& =\min (1 ; 0,25 ; 0,67) \\
& =0,25
\end{aligned}
$$

4. IF HPK BANYAK AND HPL CUKUP AND FAIL SERING THEN ADD_HPK JARANG, ADD_HPL JARANG, SLOW SERING, DOUBLE JARANG

$$
\begin{aligned}
& \alpha \text { - } \text { predikat }_{23}=\mu_{H P K_{-} \text {Banyak }} \cap \mu_{H P L_{-} \text {Cukup }} \cap \mu_{\text {FAIL_Sering }}
\end{aligned}
$$

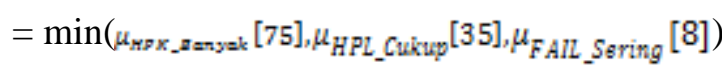

$$
\begin{aligned}
& =\min (1 ; 0,25 ; 0,33) \\
& =0,25
\end{aligned}
$$

Setelah hasil proses inferensi rule diperoleh maka dilakukan proses defuzzifikasi untuk masing-masing parameter berdasarkan rumus (1). 
Nilai Z untuk item ADD_HPK adalah :

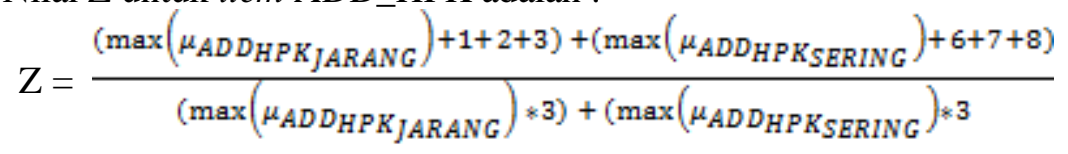

$$
\begin{aligned}
& Z=\frac{(0,67 * 6)+(0 * 21)}{(0,67 * 3)+(0 * 3)} \\
& Z=2
\end{aligned}
$$

Nilai Z untuk item ADD_HPL adalah :

$$
\begin{aligned}
& \left.\left.\mathrm{Z}=\frac{\left(\max \left(\mu_{\text {ADD }}{ }_{\text {HPL JARANG }}\right)+1+2+3\right)+\left(\max \left(\mu_{\text {ADD }}{ }_{\text {HPL }} L_{\text {SERING }}\right)+6+7+8\right)}{\left(\max \left(\mu_{\text {ADD }}\right)\right.}\right) \cdot 3\right)+\left(\max \left(\mu_{\text {ADD }} \text { HARANG }_{\text {SERING }}\right) * 3\right) \\
& \mathrm{Z}=\frac{(0,25 * 6)+(0,67 * 21)}{(0,25 * 3)+(0,67 * 3)} \\
& \mathrm{Z}=5,64 \\
& \mathrm{Z}=6
\end{aligned}
$$

Nilai Z untuk item SLOW adalah :

$\mathrm{Z}=\frac{\left(\max \left(\mu_{\text {SLOW JARANG }}\right)+1+2+3\right)+\left(\max \left(\mu_{\text {SLOW SERING }}\right)+6+7+8\right)}{\left(\max \left(\mu_{\text {SLOW JARANG }}\right) * 3\right)+\left(\max \left(\mu_{\text {SLOW SERING }}\right) * 3\right)}$

$Z=\frac{(0,67 * 6)+(0,33 * 21)}{(0,67 * 3)+(0,33 * 3)}$

$\mathrm{Z}=3,65$

$\mathrm{Z}=4$

Nilai Z untuk item DOUBLE adalah :

$\mathrm{Z}=\frac{\left(\max \left(\mu_{\text {DoubLEJARANG }}\right)+1+2+3\right)+\left(\max \left(\mu_{\text {DOUBLESERING }}\right)+6+7+8\right)}{\left(\max \left(\mu_{\text {MDOUBLEJARANG }}\right) * 3\right)+\left(\max \left(\mu_{\text {DOUBLESERING }}\right) * 3\right)}$

$\mathrm{Z}=\frac{(0,67 * 6)+(0,25 * 21)}{(0,67 * 3)+(0,25 * 3)}$

$\mathrm{Z}=3,358$

$\mathrm{Z}=3$

Berdasarkan pengujian diatas, dalam keadaan sisa HPK pemain 75 , sisa HPL pemain sebesar 35, serta jumlah kegagalan (FAIL) yang dilakukan pemain sebanyak 8 kali. Maka pemain memerlukan kemunculan item penambah HPK (ADD_HPK) sebanyak 2 kali, item penambah HPL (ADD_HPL) sebanyak $6 \mathrm{kali}$, item untuk mengurangi kecepatan game (SLOW)sebanyak 4 kali, dan item untuk menggandakan poin (DOUBLE) sebanyak 3 kali. Pengujian dilakukan sebanyak 20 kali dengan nilai input yang berbeda, dapat dilihat pada tabel berikut : 
Tabel 2. Hasil Pengujian

\begin{tabular}{|c|c|c|c|c|c|c|c|}
\hline \multirow{2}{*}{ No } & \multirow{2}{*}{ HPK } & \multirow{2}{*}{ HPL } & \multirow{2}{*}{ FAIL } & \multicolumn{4}{|c|}{ ITEM } \\
\hline & & & & ADD_HPK & ADD_HPL & SLOW & DOUBLE \\
\hline 1 & 75 & 35 & 8 & 2 & 6 & 4 & 3 \\
\hline 2 & 40 & 70 & 4 & 4 & 2 & 2 & 5 \\
\hline 3 & 80 & 90 & 1 & 2 & 2 & 2 & 7 \\
\hline 4 & 30 & 60 & 7 & 7 & 2 & 2 & 2 \\
\hline 5 & 45 & 35 & 2 & 2 & 6 & 2 & 3 \\
\hline 6 & 60 & 80 & 9 & 2 & 2 & 5 & 4 \\
\hline 7 & 78 & 42 & 5 & 2 & 4 & 2 & 4 \\
\hline 8 & 25 & 64 & 3 & 7 & 2 & 2 & 2 \\
\hline 9 & 14 & 24 & 2 & 4 & 4 & 4 & 4 \\
\hline 10 & 92 & 50 & 6 & 2 & 2 & 2 & 6 \\
\hline 11 & 62 & 40 & 7 & 2 & 4 & 2 & 4 \\
\hline 12 & 36 & 35 & 10 & 5 & 6 & 7 & 2 \\
\hline 13 & 30 & 75 & 4 & 7 & 2 & 2 & 2 \\
\hline 14 & 92 & 80 & 3 & 2 & 2 & 2 & 3 \\
\hline 15 & 15 & 10 & 6 & 6 & 6 & 3 & 3 \\
\hline 16 & 82 & 95 & 5 & 2 & 2 & 2 & 4 \\
\hline 17 & 76 & 20 & 1 & 2 & 7 & 2 & 2 \\
\hline 18 & 40 & 55 & 0 & 4 & 2 & 2 & 5 \\
\hline 19 & 28 & 60 & 8 & 7 & 2 & 4 & 2 \\
\hline 20 & 70 & 30 & 3 & 2 & 7 & 2 & 2 \\
\hline
\end{tabular}




\section{KESIMPULAN}

Dari penelitian yang telah dilakukan dapat diambil beberapa kesimpulan sebagai berikut :

1. Game dengan tema kebersihan lingkungan sungai berhasil dibuat dengan konsep Endless-Run

2. Latar belakang, tampilan objek, tampilan karakter, dibuat untuk menguatkan kesan suasana sungai

3. Metode fuzzy mamdani menjadikan jenis item yang muncul akan sesuai dengan kebutuhan dari pemain, berdasarkan atribut yang dimiliki pemain

4. Berdasarkan pengujian yang telah dilakukan, nilai $\mathrm{Z}$ terendah yang mungkin dapat diperoleh pemain adalah 2 , sedangkan nilai $\mathrm{Z}$ tertinggi yang mungkin diperoleh adalah 7

\section{SARAN}

Penulis menyadari bahwa penelitian yang dilakukan masih terdapat banyak kekurangan. Maka dari itu, terdapat beberapa hal yang dapat dikembangkan atau ditingkatkan pada penelitian yang selanjutnya, diantaranya :

1. Melakukan optimasi berkaitan dengan fungsi keanggotaan maupun rules, dll, sehingga kesan adaptif lebih kuat dirasakan dalam permainan

2. Mengkombinasikan metode yang fuzzy mamdani dengan metode lain guna meningkatkan kualitas pengambilan keputusan yang lebih baik

3. Menambahkan jenis item sehingga game menjadi lebih kaya akan fitur

\section{DAFTAR PUSTAKA}

[1] Badan Nasional Penanggulangan Bencana, "Data dan Informasi Bencana Indonesia," bnpb.go.id. [Online]. Available: http://dibi.bnpb.go.id/. [Accessed: 09-Nov-2017].

[2] Y. Allsop and J. Jessel, "Teachers' Experience and Reflections on Game-Based Learning in the Primary Classroom," Int. J. Game-Based Learn., vol. 5, no. 1, pp. 1-17, 2015.

[3] C. Sandbrook, W. M. Adams, and B. Monteferri, "Digital Games and Biodiversity Conservation," Conserv. Lett., vol. 8, no. 2, pp. 118-124, 2015.

[4] S. F. W. Utama and H. A. Wibawa, "Implementasi Logika Fuzzy Mamdani Dalam Game Simulasi Memancing," Jurnal Dinarek, vol. 11, no. 2, pp. 48-53, 2015.

[5] A. B. Harisa, H. Ali, and H. Haryanto, "TINGKAT KESULITAN OTOMATIS BERBASIS FUZZY SUGENO PADA PLATFORMER GAME BERTEMA CERITA," Semnasteknomedia 2015, 6 Februari 2015.

[6] T. Bimantoro, and H. Haryanto, "Pemodelan Perilaku Musuh Menggunakan Finite State Machine (FSM) Pada Game Pengenalan Unsur Kimia", Journal of Applied Intelligent System, Volume 1, Number 3, 2016, pp. 210-219(10).

[7] H. Haryanto, "Reward Dinamis dalam Skenario Adaptif Menggunakan Metode Finite State Machine pada Game Edukasi", Journal of Applied Intelligent System, Volume 1, Number 2, 2016, pp. 144-153(10). 